\title{
Ideation, Representation, Handwriting Realization ${ }^{\dagger}$
}

\author{
Francesca Sabattini ${ }^{1, *}$, Livia Taverna ${ }^{1}$ and Marta Tremolada ${ }^{2}$ \\ 1 Faculty of Education, Free University of Bolzano-Bozen, 39100 Bolzano (BZ), Italy; livia.taverna@unibz.it \\ 2 Department of Developmental and Social Psychology, University of Padua, 35122 Padova (PD), Italy; \\ marta.tremolada@unipd.it \\ * Correspondence: francesca.sabattini@education.unibz.it; Tel.: +39-340-683-1944 \\ + Presented at the International and Interdisciplinary Conference IMMAGINI? Image and Imagination \\ between Representation, Communication, Education and Psychology, Brixen, Italy, 27-28 November 2017. \\ Published: 5 December 2017
}

\begin{abstract}
Despite the widespread use of electronic devices for activities strictly connected to writing, several studies have proved the importance of developing handwriting, using paper and pen. One study conducted by Cutler and Graham demonstrated that the development of handwriting is so important that it may impact the academic success of a child. Moreover, different studies conducted by Graham have underlined that it is very important to give children clear and correct rules about handwriting from their early developmental stages. Effective handwriting instruction does not require a large amount of time. To see considerable returns, it is enough to spend just a few minutes every day teaching handwriting. To develop this skill, teachers need to feel prepared. The paper will propose a short excursus of suggestions dealing with how handwriting could be enhanced, underlining the importance of developing this skill from the first years of schooling as a tool aimed at preventing other possible future difficulties in the development of the person.
\end{abstract}

Keywords: handwriting; representation; instruction; composition; instructional practices

\section{Introduction}

During the first years of kindergarten, it is important to develop all those abilities, that are strictly connected to writing. Teachers should involve children with fun and stimulating exercises with the purpose of promoting fine and gross motor functioning. A good development of these skills could not only positively influence their participation in social activities but also determine the career of a student. Conversely, children that don't have the opportunity to attend the first year of schooling because of severe illness could later show significant delays in fine and gross motor skills [1,2] and manifest difficulties when re-entering school [3,4].

\section{The Importance of Handwriting Development}

Nowadays, despite the widespread use of tablets and smartphones, it is fundamental that children, from as early as kindergarten, begin to develop all those skills that are connected to the ability to handwrite. Several northern countries, such as Norway and Finland, have introduced the use of tablets in the first year of primary school. This innovation is helpful for the development of a sense of community but not for all those abilities necessary for handwriting. Writing by hand activates some parts of the brain that would not be activated by typing. This is supported by evidence indicating that the complex activity of writing results in better memory than simply typing [5]. When children begin to write they build their own idea of letters in their mind and then they translate it on to paper. Moreover, one current study suggests that students may learn to spell words more accurately through the process of handwriting [6] than by only typing. Research suggests that a keyboard should be considered only if a child's handwriting is so poor that he or she cannot meet the 
demands for written communication after all strategies have been attempted to offset this functional delay [6].

Furthermore, several characteristics of objects, such as size, color and shape, are perceived mostly by touch. There is strong evidence that suggests that writing movements are involved in letter recognition. Learning handwriting from the earliest classes is important for future academic success across many domains. For many children beginning primary school, learning handwriting can be considered a difficult challenge [7]. To confirm this, it is enough to be aware that a large proportion of students (between $10 \%$ and $34 \%$ of the entire student population) have difficulties in learning handwriting [8]. The quality of handwriting is one of the principal factors that influence academic success or failure at school because handwriting places the earliest constraints on writing development [9], and furthermore because children write for longer and longer periods of time as they progress through the grades. Moreover, difficulties in handwriting have a considerable influence on a reader's opinion. Graham [9] undertook a research in which the same text, written with two different calligraphies, was given to the same reader to be evaluated. The first text had a legible calligraphy that was pleasant for the reader, whereas the second one was difficult to read because it was poorly handwritten. While the latter was judged negatively by the participants, because it was too difficult to read, the former was positively evaluated. Unfortunately, this is also what happens daily at school: Written texts that are easily legible get higher marks than ones written with poor handwriting. Some studies that were conducted years ago showed that when teachers had to evaluate papers that were "varying only in their degree of legibility, papers with better handwriting received better grades" [10] (p. 185). This discrepancy happens because handwriting can bias readers' judgments about the ideas expressed in a text. Moreover, fluency in writing by hand can impact other writing processes, such as planning and text generation. For these reasons, it is important to ensure that students develop legible and fluent handwriting [11]. Another factor that could influence handwriting performance is the sex of students. Analysis of handwriting performance in young writers shows that girls perform better than boys [12]. In a study conducted by Weintraub, Graham and Berninger [13], sex was the third indicator of regression after finger function and visual motor integration skills in fifth-grade children. Working on handwriting could mean focusing attention on a single subject, especially if we work with boys.

Moreover, writing is not just a simple exercise of moving one's fingers and hand but is something more complex: It also means translating personal thoughts into something written and comprehensible for other readers. When children cannot form letters with reasonable legibility and speed, they cannot translate their thoughts into written text. This is one of the causes that generate a self-fulfilling prophecy for a student, in which they believe they are not able to write. These students live a discrepancy between their abilities: Most of the time, they are students who are readily able to tell you the answer to a question verbally, but struggle with handwriting. It is necessary, for this reason, to be careful because, in the worst case scenario, the student could develop an aversion to handwriting that would damage their scholastic career.

To prevent the scholarly failure that a child could encounter, it is important that teachers work on the development of all the abilities involved in handwriting from the first years of kindergarten. Dedicating just a few minutes every day to specific activities geared toward the development of handwriting is essential in order to gain benefits from handwriting [9]. One study conducted by Jones and Christensen [14] demonstrated that focused work on visuomotor aspects can positively influence the quality and quantity of a written text by increasing the legibility and fluency of the handwriting. Similar results were found with an occupational therapy intervention program with first-graders devoted to enhancing graphomotor skills [15]. The aim of the study, which was conducted in a small school in a city in the northern part of Italy, was to improve handwriting among first-grade children. An occupational therapist and a doctoral student collaborated with the class teacher in order to propose activities strictly connected to the program that the teacher had to present in her class. Fifteen six-year-old children took part in the research. During the intervention were proposed activities based on occupational therapy activities and modified for the school setting. Children worked in small groups of four. This kind of setting allowed all abilities to be stimulated through specific games. 
The training that was offered to the children in the class was planned in order to develop visual perceptual skills, fine motor skills and gross motor skills, all of which are strictly connected to handwriting. The project lasted for ten weeks, two hours a week. Children were tested three times during the project: first at T1 (baseline), before the occupational therapy intervention; then at T2 (after treatment) after the intervention; and it was then decided to test the children a third time, at T3, one month after the last intervention. Testing the children a third time enabled verification of whether the abilities were maintained over time. Moreover, a third test could be the key to confirming that a specific training could considerably increase all those abilities that are related to handwriting.

It is fair to say that investing a small amount of time from the first years of kindergarten and primary school, giving the right instruction to children for handwriting, and requesting perseverance and tenacity from teachers, is essential for the development of handwriting. For this reason, it is important to give systematic instruction because it supports the development of handwriting skills and is essential, in particular, for those children who do not write instinctively [7]. Enjoyable, creative and playful activities are preferable in order to enhance this skill. With children who are three to four years old it is possible to start by drawing points using different tools.

The Italian researchers Bravar and colleagues [16] suggested using markers, colored pencils, crayons, watercolors or washable paint. Using a paintbrush full of washable paint, a child can create a point on a sheet of paper. With the help of music, they can draw, for example, starting from the point, a circle. It is possible to play with the lines that the child draws on their paper with washable paint and recover the lines changing the material (for example, it is possible to use wool, rope, paper, etc.). Another exercise that they proposed is to ask the child to color the inner part of their drawing so that they start to see the outlines of the images with a view to improving their fine motor skills. These are only a few examples of exercises that can be proposed to stimulate the movement of the wrist used for handwriting.

Furthermore, the Italian team proposed activities with four five-year-old children that required the use of a ruler or shapes to trace the outlines. The results look more fluid and are easier to trace and recognize [16]. Moreover, it is possible to introduce geometric shapes. An American researcher called Beery [17] studied graphic traces drawn by children in different developmental phases. He defined handwriting readiness based on a child's ability to copy geometric shapes arranged in an increasingly difficulty order. Children normally draw a circle when they are 3 years old, a cross when they are 4 years old and a triangle when they are approximately 6 years old [18] (p. 983). He presented a list of nine figures that a child who is ready for handwriting should draw without difficulty. These figures are: 1 . a vertical line; 2 . a horizontal line; 3 . a circle; 4 . a cross; 5 . a right oblique line; 6 . a square; 7. a left oblique line; 8. an oblique cross (X); 9. a triangle [18] (p. 983). The Beery-Buktenica Developmental Test of Visual-Motor Integration is a tool that is used for rapid screening to assess a person's ability to integrate visual and motor skills [17]. The test could be used with children at kindergarten as an indicator of handwriting readiness [18]. If a child successfully performs the first nine figures of the Beery VMI test, that could be used as an indicator of handwriting readiness for formal writing. Weil and Cunningham Amundson [18] reported that kindergarten children who were able to copy the first nine figures (vertical line, horizontal line, circle, cross, right oblique line, square, left oblique line, oblique cross and triangle) were able to copy significantly more letters than those that were not able to copy the first nine figures [17]. The information that can be collected from the VMI test is useful for teachers and educators in identifying children's handwriting readiness and in designing specific activities aimed at improving fine motor, gross motor and postural stability skills.

The transition from kindergarten to primary school is very important for children for developing fine motor skills and graphomotor skills. It is during the first years at school that children complete the development of fine motor skills and become competent handwriters [12]. A competent handwriter is someone who is able to write legibly, fluently, with sufficient speed for all practices and without strain because writing is one of the most important abilities and is not only necessary at school but for many activities in life. One important skill in the development of handwriting is learning how to write the letters of the alphabet correctly. Some letters are easier than others to write because they differ in terms of the number, direction and types of strokes [19]. A research conducted 
by Graham [9] suggests starting teaching handwriting by using traditional manuscript letters. There are four good reasons for this. First, children come to primary school already knowing some of the letters of the alphabet that their kindergarten teachers or parents have taught them. Secondly, there is some evidence that learning traditional manuscript handwriting is easier than cursive writing. Third, when traditional manuscript is learnt, it will be written faster and more legibly than cursive writing. Fourth, traditional manuscript handwriting can facilitate the development of reading [9].

As part of the class routine, it is very important to reinforce handwriting on a daily basis, exposing children to diverse types of games, individually or in groups. Practice is considered a key component of handwriting and motor learning. Children who present handwriting difficulties require constant practice to master letter formation without worrying about content and grammar.

During the everyday routine it is possible to propose several types of activities that could support both gross and fine motor development. Gross motor development, for example, involves control of the arms, legs, head and trunk. During the daily routine it is possible to create different opportunities for children to run, jump, hop, throw and catch, and climb up, down and through things so they can develop the muscles involved in writing.

On the other hand, fine motor development involves careful control of the small muscles in the hands, feet, fingers and toes. For example, children can be asked to pick up small objects using the first three fingers of the hand (thumb, index finger and middle finger) or using tweezers to collect small objects like coins, raisins or little stones. Games could be easily invented or found in books or on the Internet. Games that could be proposed to children at kindergarten have a fundamental importance in the development of handwriting, which will begin, formally, from the first years of primary school.

Several studies have been conducted in the United States of America in which teachers were asked how much time they spend on teaching handwriting beginning from the first grade. The survey confirmed that teachers usually dedicate 30 min every day to teaching handwriting. The rest of the hour, typically about 30 minutes, they dedicate to teaching a variety of writing strategies and techniques [13]. On the other hand, teachers declared that they spend less time using computers in order to develop writing (they said they use computers less than $60 \%$ of the time each month).

Teaching handwriting is a very important skill, not least because nearly $70 \%$ of salaried employees have at least some responsibilities involving writing [20] (p. 6). Directly connected to this, it is easy to understand why teachers play a considerable role.

Teaching handwriting can be considered an art. It can be managed independently from teacher to teacher. A recent review of the Italian National Guidelines for primary schools from 1860 until today [21] demonstrated that the attention dedicated to teaching handwriting has decreased considerably. Significant attention has been devoted to linguistic, spelling and syntactic aspects of writing.

The Education Ministerial Guidelines for the kindergarten and primary school curriculum of 2012 [22] underlined the importance of developing the linguistic, spelling and syntactic dimensions with the purpose of communicating in different contexts and for different readers. Teachers should teach children, from the first grade, to emphasize why they are writing and to convince the reader. The Education Ministerial Guidelines state that from kindergarten children should come across the written language, explore and play with different forms of written language, and meet new digital technologies and media (Original text: “...il bambino si avvicini alla lingua scritta, esplori e sperimenti le prime forme di comunicazione attraverso la scrittura, incontrando anche le tecnologie digitali e i nuovi media ...". Indicazioni Nazionali, 2012.) [22] (p. 21). In those guidelines, no mention is made of either handwriting or motor skills, which scientists affirm should be practiced daily from kindergarten. Focusing on the Italian situation, there is no mention in the Education Ministerial Guidelines regarding the teaching of handwriting related to various age levels. Because of the lack of guidelines from the Education Ministry, kindergarten teachers are asked to propose projects in regard to first handwriting literacy based on unclear aims to prepare children for the entrance at primary schools. Also, in the United States teachers have underlined the complete absence of specific training regarding pedagogical gestures. Only $28 \%$ of American teachers report that they are adequately 
prepared to teach handwriting at school, while $44 \%$ declare that they feel unready to teach handwriting because they are not sufficiently competent in that area [23]. The absence of concrete rules could be a barrier for all those teachers who have not received a complete professional education and have to teach handwriting.

It is important to give early handwriting instruction starting from the pencil grip to the formation of letters. Teachers should begin demonstrating how to hold the pencil correctly between the thumb and forefinger, resting on the middle finger. After a while, students will find their own comfortable pencil grip in order to avoid fatigue. Children will change their pencil grip. Initially they will have an immature grip when they first hold pencils or crayons [24]. Then, this will develop into mature grip patterns, which include, but are not limited to, the tripod grip. Children aged four to six will develop a tripod grip that they will continue to refine up to the age of 14 [24]. There are children who will never grasp the pen with a tripod grip. What is important for them is that they find a comfortable grip and don't suffer pain in their hand, wrist and arm. Teachers do not have to correct grips because each child will have their own grip that should be the most comfortable and productive for them. At the same time, teachers should show children how to form legible and fluent letters by practicing them daily. One suggestion regarding writing instruction is that teachers who teach in the same class should give and follow the same writing rules to limit confusion in young learners. Cutler and Graham [23] demonstrated that there are different approaches to teaching writing: $65 \%$ of teachers reported that they did not use a commercial program to teach writing, handwriting, spelling or any other aspect of writing. The other $35 \%$ of the teachers listed 137 different programs they used. The most common programs (45\%) were designed to teach either handwriting or spelling [23]. Researches have demonstrated that letters should be introduced in a specific order that should be carefully considered. For example, letters that could be easily confused ("b" and " $d$ ") or vowel sounds that are difficult to distinguish ("sad" and "bed") should be taught separately [25].

Looking back at all the different studies that we have mentioned, it is possible to rethink a pedagogy of writing that does not refer to the nineteenth- century idea of clear calligraphy, but focuses more on handwriting development strictly connected to children's well-being. This concept finds support in the idea that children have to develop writing skills and become more confident with writing so that their attention can be focused more on developing and communicating their ideas and not on the simple act of writing. Moreover, it will be necessary to dedicate time in class during all lessons to practice handwriting.

A mistaken belief is that handwriting should only be practiced during a specific lesson (this could be Italian, German or English) and not during other disciplines. A study conducted by Graham et al. [19] indicated that young learners spend 30 min every day writing (in this case, the word "writing" means all kinds of writing). Writing doesn't only mean writing something on a piece of paper, it means leaving a written thought that has a concrete meaning and that is understandable to all readers.

When students have become confident with handwriting using a pen and paper they can learn to type with a computer. Teachers should guide students through the basic skills of computer usage, such as turning on a PC, writing and saving files, etc., as well as typing a short text that can be understood by a range of different audiences. This type of writing is only possible when children have learnt handwriting because many children who struggle with automatic handwriting may also struggle with automatic keyboarding [6] (p. 224).

The Parliament and the European Council, in the Recommendation of 18 December 2006 [26], identified eight key competences for long-life learning. One of those competencies is the development of digital knowledge. Among the competencies that a child has to gather up to the end of the fifth grade is the ability to produce, by himself/herself or in groups, digital documents for different audiences (texts, presentations, e-mails, cognitive maps, etc.) and the ability to understand different destinations and communicative functions [27]. The document has the purpose of introducing different technological tools that are useable in class.

In Italian classes, the interactive whiteboard (IWB) has become more widely used. The IWB is an interactive board that combines the characteristics of a traditional board with a more sophisticated 
technology, guaranteed by the use of a PC. With the IWB, it is possible to display images onto a board using a digital projector. This is an innovative idea aimed at stimulating and motivating students to create texts, especially for all those children who have handwriting difficulties. In fact, children can write their own text and manipulate it with the help of classmates. The IWB provides the opportunity to work in a collaborative way, because it is possible to add annotations, highlight text, add notes and drawings or add pictures. With the IWB, it is also possible to save all files and create a printable copy or share it by email. What is important is that with the IWB it is possible to write by hand. A simple program used for writing can recognize what children write and convert the text into static text. Using an IWB can be helpful, especially for all those children to whom handwriting appears difficult. With an IBW, even children who have handwriting difficulties can write and translate their own thinking into a written text without fear of being negatively judged. Moreover, it is possible to imagine that children who avoid handwriting could be more encouraged to create their own work without the typical worry that characterizes children with handwriting difficulties.

Nevertheless, learning and developing handwriting skills is always very important for all children so that they can use them in many other different contexts of daily life and not only at school.

\section{Conclusions}

Developing handwriting is for all children a very important skill. In this paper, it was given an overview about the diverse aspects that are required in order to be effective in developing handwriting at school. Moreover, we have reported a few examples of techniques that could be spend since the first class of kindergarten to develop all those abilities related to graphomotor skills. These suggestions are usable as prevention with all the children and not only with those who show difficulties in handwriting because "handwriting remains one of the most direct and efficient forms of graphic communication" [28] (p. 879) that permit to people to communicate and leave a personal thought to other readers.

Author Contributions: Francesca Sabattini researched and studied the material used to write the article, wrote the article and the final version of the paper; Livia Taverna was in charge to shape the research, supervised the review study, provided critical feedback, commented on the manuscript and edited the final version of the paper. Marta Tremolada provided critical feedback and commented on the manuscript.

Conflicts of Interest: The authors declare no conflict of interest.

\section{References}

1. Taverna, L.; Tremolada, M.; Bonichini, S.; Basso, G.; Pillon, M. Adaptive Functioning of Preschooler Children with Leukemia Post 1 Year of Therapies Compared with Sane Peers. Br. J. Educ. Soc. Behav. Sci. 2016, 8, 1-15.

2. Taverna, L.; Tremolada, M.; Bonichini, S.; Tosetto, B.; Giuseppe, B.; Messina, C.; Pillon, M. Motor skill delays in pre-school children with leukemia one year after treatment: Hematopoietic stem cell transplantation therapy as an important risk factor. PLoS ONE 2017, 12, e0186787. doi:10.1371/journal.pone.0186787.

3. Tremolada, M.; Bonichini, S.; Taverna, L.; Pillon, M.; Basso, G. I pazienti pediatrici curati per leucemia che tornano a scuola: Analisi delle narrazioni su vita quotidiana ed esperienza di malattia. Psicol. Clin. Dello Svilupp. 2017, in press.

4. Tremolada, M.; Sbalchiero, F.; Bonichini, S.; Pillon, M.; Carli M. Il comportamento adattivo in 50 bambini malati di leucemia nell'ultimo anno di terapia: Un'analisi longitudinale, Adaptive behavior in 50 children with leukaemia during the last therapy year: A longitudinal study. Psicol. Clin. Dello Svilupp. 2011, 3, 625-646.

5. Timothy, J.S.; Carrie, E.M.; Alison, K.R. Comparing memory for Handwriting versus Typing. Proc. Hum. Fact. Ergon. Soc. Ann. Meet. 2009, 53, 1744-1747, doi:10.1177/154193120905302218.

6. Cahill, S.M. Where Does Handwriting Fit In? Strategies to Support Academic Achievement. Interv. School Clin. 2009, 44, 223-228, doi:10.1177/1053451208328826. 
7. Taverna, L. Quando un bambino è pronto per imparare a scrivere? In Psicologia Per Una Buona Scuola; Libreria Universitaria Edizioni: Limena PD, Italy, 2016; pp. 81-95.

8. Smits-Engelsman, B.C.M.; Niemeijer, A.S.; van Galen, G.P. Fine motor deficiencies in children diagnosed as DCD based on poor grapho-motor ability. Hum. Mov. Sci. 2001, 20, 161-182.

9. Graham, S. Want to Improve Children's Writing? American Educator, 2009-2010; pp. 20-40. Available online: https://www.aft.org/sites/default/files/periodicals/graham.pdf (accessed 25 August 2017).

10. Hammerschmidt, S.L.; Sudsawad, P. Teachers' survey on problems with handwriting: Referral, evaluation, and outcomes. Am. J. Occup. Ther. 2004, 58, 185-192.

11. Santangelo, T.; Graham, S. A Comprehensive Meta-analysis of Handwriting Instruction. Educ. Psychol. Rev. 2015, doi:10.1007/s10648-015-9335-1.

12. Feder, K. P., Majnemer, A., Bourbonnais, D., Plat, R., Blayney, M., Synnes, A. Handwriting performance in preterm children compared with term peers at age 6 to 7 years. Dev. Med. Child Neurol. 2005, 47, 163-170.

13. Graham, S., Weintraub, N., Berninger, V. Which manuscript letters do primary grade children write legibly? J. Educ. Psychol. 2001, 93, 488-497, doi:10.1037//0022-0663.93.3.488.

14. Jones, D., Christensen, C.A. Relationship between automaticity in handwriting and students' ability to generate written text. J. Educ. Psychol. 1991, 91, 44-49, doi:10.1037/0022-06673.91.1.44.

15. Taverna, L.; Tremolada, M.; Sabattini, F.; Tosetto, B. Intervenire a scuola. L'ergoterapia a servizio della scrittura. GITO 2017, 19, 5-15.

16. Bravar, L.; Gortana, M.; Dengo, M.; Borean, M.; Biancotto, M.; Zoia, S. Le difficoltà grafo-motorie nella scrittura. In Proposte Operative Dalla Prevenzione All'intervento; Erickson: Trento, Italy, 2014; ISBN 978-88590-0639-8.

17. Beery, K.E. The Developmental Test of Visual-Motor Integration, 3rd ed.; Modern Curriculum Press: Cleveland, OH, USA, 1989.

18. Weil, M.; Cunningham Amundson, S. Relationship Between Visuomotor and Handwriting Skills of Children in Kindergarten. Am. J. Occup. Ther. 1994, 48, 982-989. (accessed on 25 August 2017)

19. Graham, S.; Harris, K.R.; Fink-Chorzempa, B.; MacArthur, C. Primary grade teachers' instructional adaptations for struggling writers: A national survey. J. Educ. Psychol. 2003, 95, 279-292.

20. Graham, S.; Bollinger, A.; Booth O.C.; D'Aoust, C.; MacArthur, C.; McCutchen, D.; Olinghouse, N. Teaching Elementary School Students to be Effective Writers: A Practice Guide (NCEE 2012-4058); National Center for Education Evaluation and Regional Assistance: Washington, DC, USA; Institute of Education Sciences, U.S. Department of Education: Washington, DC, USA, 2012. Available online: https://ies.ed.gov/ncee/wwc/ publications_reviews.aspx\#pubsearch (accessed on 15 July 2017).

21. Venturelli, A. Il Corsivo: Una scrittura per la vita. In Prevenzione e Recupero Della Disgrafia; Mursia: Milano, Italy, 2009; ISBN 978-8842543138.

22. Ministero Dell'istruzione Dell'università e Della Ricerca. Indicazioni Nazionali Per il Curricolo Della Scuola Dell'infanzia e Del Primo Ciclo D'istruzione. 2012. Available online: http://www.indicazioninazionali.it/documenti_Indicazioni_nazionali/indicazioni_nazionali_infanzia_pri mo_ciclo.pdf (accessed on 27 July 2017).

23. Cutler, L.; Graham, S. Primary Grade Writing Instruction: A National Survey. J. Educ. Psychol. 2008, 100, 907-919, doi:10.1037/a0012656.

24. Schwellnus H. D. Pencil Grasp Pattern: How Critical is it to Functional Handwriting? Degree of Doctor of Philosophy Graduate Department of Rehabilitation Science; University of Toronto: Toronto, ON, Canada, 2012; in press.

25. Troia, G.A.; Graham, S. Effective Writing Instruction Across the Grades: What Every Educational Consultant Should Know. J. Educ. Psychol. Consult. 2003, 14, 75-89. Available from: http://www.writing.ucsb.edu/wrconf08/Pdf_Articles/TroiaArticle.pdf (accessed 27 July 2017).

26. Parlamento Europeo e Del Consiglio. Raccomandazione Del Parlamento Europeo e Del Consiglio Del 18 Dicembre 2006 Relativa a Competenze Chiave Per L'apprendimento Permanente. 2006. Available online: http://www.amblav.it/Download/1_39420061230it00100018.pdf (accessed on 5 July 2017). 
27. Provincia Autonoma di Bolzano. Indicazioni Provinciali Per la Definizione Dei Curricoli Del Primo Ciclo D'istruzione Della Scuola in Lingua Italiana Della Provincia Autonoma di Bolzano. 2015. Available online: http://www.provincia.bz.it/intendenza-scolastica/service/pubblicazioni.asp (accessed on 10 July 2017).

28. Maldarelli, J.E.; Kahrs, B.A.; Hunnt, S.C.; Lockman, J.J. Development of Early Handwriting: Visuo-Motor Control during Letter Copying. Dev. Psychol. 2015, 51, 879-888. Available online: http://dx.doi.org/10.1037/a0039424 (accessed 12 July 2017).

(C) 2017 by the authors. Licensee MDPI, Basel, Switzerland. This article is an open access article distributed under the terms and conditions of the Creative Commons Attribution (CC BY) license (http://creativecommons.org/licenses/by/4.0/). 